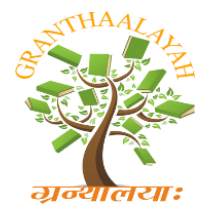

INTERNATIONAL JOURNAL OF RESEARCH GRANTHAALAYAH A knowledge Repository

Social

\title{
SOCIAL SUPPORT AND JOB SATISFACTION AMONG THE SCHOOL TEACHERS IN TIRUCHIRAPPALLI EDUCATIONAL REVENUE DISTRICT, TAMIL NADU, INDIA
}

\author{
R. Rajakala *1, Dr. S. Sampath Kumar ${ }^{2}$ \\ ${ }^{* 1}$ Research Scholar, Department of Sociology, Bharathidasan University, Tiruchirappalli-620 \\ 024, Tamil Nadu, INDIA \\ ${ }^{2}$ Assistant Professor, Department of Sociology, Bharathidasan University, Tiruchirappalli-620 \\ 024, Tamil Nadu, INDIA
}

\begin{abstract}
Teachers' role in society in general and in education has been changing with time but the importance of this position is same. The teacher is the pre-requisite of the success of educational programmes. The main quality of teacher is the positive attitude towards education. One of the effective factors on job satisfaction is perceived social support by individuals. One of the psychological concepts that have been introduced by scientists of educational science is social support. It was among the basic needs of human beings throughout the history. Data were collected from 70 males and 312 female teachers working in both rural and urban schools in Tiruchirappalli revenue district using systematic random sampling techniques. The results reveal that there is no relationship between social economic variables (gender, age, and education) and social support; however marital status and income are positively associated with social support. The results further expose that social economic variables (age and education) are negatively linked with job satisfaction. Hence, better social support and higher job satisfaction of teachers.
\end{abstract}

Keywords:

Social Support, Job Satisfaction, school teachers.

Cite This Article: R. Rajakala, and Dr. S. Sampath Kumar, "SOCIAL SUPPORT AND JOB SATISFACTION AMONG THE SCHOOL TEACHERS IN TIRUCHIRAPPALLI EDUCATIONAL REVENUE DISTRICT, TAMIL NADU, INDIA" International Journal of Research - Granthaalayah, Vol. 3, No. 12(2015): 83-91.

\section{INTRODUCTION}

Education is a continuous process. It may be formal, informal or non-formal. In formal education teacher has a very important place in improvement of education. Teachers' role in society in general and in education has been changing with time but the importance of this position is same. 
The teacher is the pre-requisite of the success of educational programme. The main quality of teacher is the positive attitude towards education .They must have the ability to get satisfied from their respective jobs. Job satisfaction is a favorableness with which workers view their job. It results when there is a fit between job requirement and the wants and expectations of employees. In other words, it expresses the extent of match between worker's expectations (also aspiration) the rewards, the job provides, the values it creates and get cherished. Job satisfaction includes feelings and attitudes that everyone has about his/her job in a comprehensive definition. All aspects of a certain job such as good and bad, positive and negative aspects effect on satisfaction and dissatisfaction feeling (Imbert, 2004).

One of the effective factors on job satisfaction feeling is perceived social support by individuals. One of psychological concepts that have been introduced by scientists of educational science is social support. It was one of the basic needs of human beings throughout the history. Balbi (1982) believes that (quoted by RastegarKhaled, 2005) humans can face crisis, threats and dangers during human history through help by others. Thus, need to close attachment have been established and we can use support from family, friends and others. Social support is offered to enjoyment of love, support and attention of co- workers, supervisor, institutions, family members and friends. Many studies revealed that social support is one of the real elements on job satisfaction.

Teacher supportive work is defined as a mechanism to encourage and facilitate teachers' broader involvement with peers and colleagues in school, parents and students or beyond sharing responsibility and solving problems more effectively towards the same common goal. Teachers work together via frequent meetings, sharing ideas, seminars, discussions, to plan and review the curriculum, discuss students' progress and how to assess it, to plan and review lessons in detail regardless the size of enrolment or the location of the school. In addition, participation and involvement in extra-curricular activities, school programs and functions, in-service trainings also will be taken into account. The work of individual teachers in class and school is thus supported by consistent collaboration from school leaders, colleagues and community. The actual needs of supportive work are teachers' actual involvements that occurred in Commission onPublic Secondary School (CPSS) whereas the required needs of collective work are the expected level of collective work that the teachers need in their workplace.

\section{REVIEW OF LITERATURE}

The study conducted in Ghanaian among 170 female managers from 51 private organizations, 59 Public organizations, and 60 from multinational organizations. The results have shown that social support was negatively and significantly related to managerial women's mental health. Supervisory support, co-worker support, and friend support were not significantly related to mental health and although the women find coworker support helpful, this support has nothing to do with their mental health. A woman's tendency to use problem-focused (social support) coping was shown to be a significant predictor of health outcomes. The results also showed that spousal support was significantly and negatively related to mental health and spousal support appears to be especially important to married women. Two-thirds of the women reported that they had the active support and encouragement to work from their spouses. Spousal support provides a sense of security and stability at home and reduces role conflict (JocelynSackey 2011). 
The study consists of 170 (112 male 58 female) teachers in Pakistan reveals that perceived organizational support has significant relationship with employee retention, with a mediator between perceived organizational support and employee retention. Psychological empowerment has significant relationship with faculty retention and also play role as mediator between perceived organizational support and employee retention. (SehreshIqbal 2015)

The study consisting of 201 teachers from Chinese private secondary schools in Penang, Malaysia shows that there is a moderate, positive and significant relationship between the principal support and the needs of combined work gained by teachers. Thus the needs of combined work required by the teachers and principal's concern of teacher welfare are the significant predictors toward the needs of combined work gained by teachers. (KeowNgang and Lye Phei2013)

A study conducted in Bangladesh among 375 respondents randomly selected expose that salary and motivation are the most important factors for influencing job satisfaction of employees. Salary is most important, but working condition, supervisor supports, appraisal technique, work training, grievance handling, safety provision, and work life balance are critical factors for determining employees' job satisfaction. (JobaidImrul 2015)

The study consisted on 436 teachers on Impact of Students' profile on job Satisfaction of the teachers in Tirunelveli District depicts that the job satisfaction of the teachers in the schools of Private, Government Aided, and Government. There were five factors (performance and appraisal, recognition, career scope, teachers' introversion and service norm) that affect the satisfaction of the teachers on the profession. Moreover, it is fruitful to understand that the satisfaction of the teacher is not affected by the suburban area, wealthiness of the family, and social reputation of the student. However, the teachers' satisfaction was affected by the educational background of the family of the student. (Rajalingam, 2014)

A study conducted by SandeepKataria (2014) in Moga district of Punjab among 200 government and private school teachers. Significant differences were found in the mean scores of private school teachers with respect to gender and locality, where asno association were found in the mean scores of government school teachers with respect to gender and locality.

\section{OBJECTIVES}

- To study the relationship between socio- economic status and professional status of the teachers with job satisfaction.

- To study the relationship between socio- economic and professional status with Social Support.

- To explore the link between social support and job satisfaction.

\section{UNIVERSE AND SAMPLING}

The population for the purpose of this study has been defined as school teachers of Tiruchirapalli educational revenue district. The researcher adopted multistage random sampling technique to determine the sample frame. The Tiruchirappalli educational revenue district is considered as 
broad area of research, it consist of two rural (Srirangam, Thiruverambur) and two urban (Tiruchirappalli, Manapparai) blocks.

In the first stage of sample selection, the researcher has selected Srirangam as a rural block and Tiruchirappalli as an urban block by using lottery method. The chosen blocks consist of 468 (245 urban and 223 rural) schools of all levels, out of which selection of 20 percent of schools (49 urban and 45 rural) considered as second stage of sample selection again adopting the lottery method. As the third stage, the researcher identified total of 1272 teachers (235 male and 1037 female) in the 93 schools and it was decided to take 30percent (382) of them as a sample (70 males and 312 females) using systematic random sampling techniques. The researcher gave an equal representation to teachers of primary, middle, secondary and higher secondary schools of both in the rural and urban schools.

\section{TOOLS AND COLLECTION OF DATA}

The Karasek's (1981) social support scale was adopted by adding eight items of family support component and the investigator adopted job satisfaction scale, which was developed by Jenitta (2013). The pilot study was done to check the feasibility of the tool and Cronbach Alpha reliability test was conducted to assess the reliability of the questionnaire. The data were collected using structured questionnaire from the teachers from March to April, 2015.

\section{RESULTS AND DISCUSSION}

\section{SOCIO ECONOMIC CONDITIONS}

The data's related to socio-economic status of the respondent's gives valuable lead to any social science study and further it provides detailed and deeper assessment with the main study variables. In the present study 312 are female teachers and 70 male teachers were chosen as sample, in which almost 50 percent of the teachers are aged between 28-32, 33-37 and 43-47 age groups and50 percent of them belongs to backward caste and 60 percent of them are Hindus. With regard to the educational status, majority of them $(92 \%)$ have under graduate and post graduate degree. The emphasis of distance and continuing education were teachers are given chance to update and enhance the qualification level. The income pattern depicts that, 50 percent of them fall into the middle income group of Rs 15,000 to Rs. 35,000. The monthly income of the respondent is seen to be related to the years of service. The general pattern observed is that, the lower the years of service, the lower the monthly income and vice versa. From the level of education, occupation and monthly income it can be concluded that the respondents belong to the upper- middle class status group. Majority of their spouses are from same profession and thus discloses that 90.5 percent belong to the "dual career' families.

\section{PROFESSIONAL STATUS}

The teachers are working both in the rural and urban located schools. Travelling time of the teachers to and from the school is quite considerable and led to slight unproductiveness. Teachers are important for the student in learning of specific subjects and over the period of 
time, they got fed up with the unchallenging system which does not demand any of their expertise or experience in the day to day functioning of the school.

The probable reason is that the teachers who hold higher positions in schools have less number of teaching periods and they were more involved in other more challenging administrative duties in their schools. The data shows that 70 percent of them are having work experience of 5 years and lower to 10 years and 65 percent of teachers holding the position of senior and under graduate teachers. The respondents seem to have a bearing on their job position, usually, as one advance in age and qualification, their occupational designation also steps forward.

Table 1: Association between Socio-Economic Status and Social Support

\begin{tabular}{|lllll|}
\hline S.No & Variables & $\mathbf{X}^{\mathbf{2}}$ & $\mathbf{d f}$ & Value \\
\hline 1 & Gender & 1.720 & 1 & .224 \\
2 & Age & 7.183 & 6 & .307 \\
3 & Education & 0.530 & 2 & .775 \\
4 & Place of Residence & 0.358 & 1 & .574 \\
5 & Income & 41.485 & 6 & $.000^{* *}$ \\
6 & Marital Status & 6.186 & 2 & $.044^{*}$ \\
\hline
\end{tabular}

** 0.01 Level, *0.05 Level

The analysis (Table: 1) brought out the association between social economic status of the teachers and social support components shows no significant relationship between the gender and social support. The teachers of both sex perceived low level of social support (.224>0.05, $\mathrm{p}$ value $<0.05)$.There is a negative association between the age and social support. The age group of the teachers between 33-37 years would receive more support from all as a reciprocation of their established relationship. In the other age group of the teachers have no social support (.307> 0.05, p value < 0.05). The educational status had shown no impact on social support components. The institutional culture is the product of institutional policies and practices, it is not necessary that in every institution the same set of dimensions of culture must explain why some teachers are more and some are less motivated. This is because each organization is a unique social system in terms of the sum total of its policies and procedures $(.775>0.05, \mathrm{p}$ value $<0.05)$. The component based analysis shows that, irrespective of the place residence teachers exposed weak relationship with social support components except their association with the family and on the whole analysis showing no significant association between place of residence and social support $(.574>0.05, \mathrm{p}$ value $<0.05)$. The income factor shows positive association with the social support $(.000<0.05, \mathrm{p}$ value $<0.05)$. Hence, higher the income of the teachers receives better social support. The married teachers are receiving better social support, obviously the results indicates that there is positive association between the marital status and social support $(.044<0.05$, $\mathrm{p}$ value $<0.05)$.

Table 2: Association between Socio - Economic Status and Job Satisfaction

\begin{tabular}{|lllll|}
\hline S.No & Variable & $\mathbf{X}^{\mathbf{2}}$ & Df & Value \\
\hline 1 & Gender & 21.109 & 1 & $.000^{* *}$ \\
2 & Age & 4.625 & 6 & .599 \\
3 & Education & 2.780 & 2 & .243 \\
5 & Income & 27.047 & 6 & $.000^{* *}$ \\
\hline
\end{tabular}




\begin{tabular}{|lcccc|}
\hline 6 & Marital Status & 0.027 & 2 & .987 \\
$* * * 0.01$ Level, $* 0.05$ Level & & & \\
\hline
\end{tabular}

The inferential analysis (Table: 2) test the association between social economic status of the teachers and job satisfaction. The gender shows positive association with job satisfaction. Irrespective of the gender, the teachers are showing equal level of satisfaction since same educational policy, working conditions, working nature etc. $(.000<0.05$, $\mathrm{p}$ value $<0.05)$. The result indicates that education qualification doesn't have statistically significant associated with job satisfaction. The reason could be the range of educational qualification of the teachers not fetching any career lift and they follow fixed curriculum, which not requires update and innovation. Hence, the upgraded knowledge gained through new learning are not welcomed by the school $(.599>0.05, \mathrm{p}$ value $>0.05)$. The income has a statistically no significant relationship with job satisfaction. It's also found that the teachers, who are fresh graduates with higher qualification are not satisfied with the job, since because experienced less qualified teachers are fetching more salary than them $(.243>0.05, \mathrm{p}$ value $>0.05)$. The teacher felt that they are paid with all the benefits and allowance more than their contribution to the work. Itis a clear indictor that the higher the income led to better the satisfaction toward their job.Hence, the income is statistically has positive association with job satisfaction $(.000<0.05$, p value $<0.05)$. The marital status momentously associated with job satisfaction $(.987>0.05$, $\mathrm{p}$ value $<0.05)$.Despite the fact that the married teachers tend to contribute lot to family commitments, less freedom, lack of sharing, work and family pressure, no personal development. Hence, married teachers cannot concentrate fully on the job and career advancement.

Table 3: Association between Professional Status and Social Support

\begin{tabular}{|lllll|}
\hline S.No & Variables & $\mathbf{X}^{\mathbf{2}}$ & df & Value \\
\hline 1 & Place of School & 11.139 & 1 & $.001^{* *}$ \\
2 & Nature of School & 18.486 & 3 & $.000^{* *}$ \\
3 & Types of School & 0.871 & 2 & .647 \\
4 & Year of Experience & 24.552 & 5 & $.000^{* *}$ \\
5 & Teaching Hours & 25.346 & 3 & $.000^{* *}$ \\
6 & Present Position & 6.099 & 2 & .107 \\
\hline
\end{tabular}

The analyses (Table: 3 ) assess the association between professional statuses of the teachers with social support components, in which the place of school is positively associated with social support. Irrespective of the place of school (Rural and Urban) teachers receive better social support like; emotional support such as caring and empathy and instrumental support to solve problems and information exchange. The principal support and the needs of collective work and the organizational support gained by teachers is very well balanced because of no difference to the education policy, welfare, and working conditions between rural and urban schools(.001 $<0.05, \mathrm{p}$ value $<0.05)$. The data indicates that there is statistically significant relationship between nature of school and social support component. The middle school teachers comparatively scored low in the social support component than that of other sections of teachers $(.000<0.05, \mathrm{p}$ value $<0.05)$. The study indicates that the government school teacher are having better earning and flexible pressure free working schedule, cordial relationship with their colleagues than that of private school teachers, who have no enough pay, heavy work load, 
dominating colleagues, administrative work, no encourage from the head and organization and more than that family commitment, hence the analysis shows that type of school negatively associated with social support $(.647>0.05, \mathrm{p}$ value <0.05). The years of experience of the teachers are statistically significant relationship with social support component. The class interval of years of experience of the teachers denotes that the less and moderately experienced teachers are enjoying enhanced social support than that of more experienced teachers, but the difference is so moderate $(.000>0.05$, $\mathrm{p}$ value $<0.05)$. The teachers who having lesser teaching hours scored low in the social support component than the teachers having more hours of teaching, but the data shows statistically significant relationship between hours of teaching with social support $(.000>0.05$, $\mathrm{p}$ value $<0.05)$. The current position of the teachers is not significantly associated with components of social support. Irrespective of the current position, the teachers comparatively scored high in the social support components $(.107>0.05$, p value $<0.05)$.

Table 4: Association between Professional Status and Job Satisfaction

\begin{tabular}{|lllll|}
\hline S.No & Variables & $\mathbf{X}^{\mathbf{2}}$ & $\mathbf{d f}$ & Value \\
\hline 1 & Place of School & 1.555 & 1 & .218 \\
2 & Nature of School & 21.807 & 3 & $.000^{* *}$ \\
3 & Types of School & 1.631 & 2 & .446 \\
4 & Year of Experience & 11.429 & 5 & $.036^{*}$ \\
5 & Teaching Hours & .958 & 3 & $.000^{* *}$ \\
6 & Present Position & 20.965 & 3 & .814 \\
\hline
\end{tabular}

** 0.01 Level, * 0.05 Level

The association is assessed between professional status and job satisfaction of the teachers. The place of school negatively associated with job satisfaction $(.218>0.05, \mathrm{p}$ value $<0.05)$. The teachers who are working in the rural schools face the difficult of travel and minimum transport facilities and have no proper basic needs. The teachers are placed in the different nature of schools as per the qualification they earned; hence they are satisfied with their job $(.000<0.05, \mathrm{p}$ value $<0.05$ ). The private school teachers comparatively have less job satisfaction than that of government and aided school teachers, noticeably type of school negatively associated with job satisfaction $(.446<0.05, \mathrm{p}$ value $<0.05)$. The findings indicated statistically significant relationship between years of experience and job satisfaction. Teachers with year of experience of below 5 years and 6-10 years had higher satisfaction level, because the senior teachers once as they have served the systems for longer duration and are being able to adept with the system. The other probable reason could be the younger teacher are more ambitions that of the older $(.036<$ $0.05, \mathrm{p}$ value $<0.05)$. The results indicate that more the teaching hours more was satisfaction level. The teachers are more satisfied with the amount of teaching hours without other burdens than those teachers who have less number of teaching hours $(.000<0.05$, p value $<0.05)$ and current position of the teachers is statistically not significantly associated with job satisfaction, however the component wise analysis indicates that irrespective of the current position, the teachers are satisfied with their job $(.814<0.05$, $\mathrm{p}$ value $<0.05)$.

Table 5: Association between Social Support and Job Satisfaction

\begin{tabular}{|llllll|}
\hline Source & Sum of Squares & Df & Mean Square & F & Sig \\
\hline Between Groups & 40638.284 & 48 & 846.631 & 10.016 & $.000^{* *}$ \\
Within Groups & 28147.684 & 333 & 84.528 & & \\
\hline
\end{tabular}




\begin{tabular}{lll}
\hline Total & 68785.969 & 381
\end{tabular}

The results show that there is a significant relationship between social support and job satisfaction $(.000<0.05$, $\mathrm{p}$ value $<0.05)$. When compared to the social support rendered between the groups, the support render within the groups seems to be lesser, but the teachers who get support from the family, co-workers and head of the institution are having better job satisfaction,

\section{CONCLUSION}

Teachers are need a continuous renovation and experiencing a sense of inadequacy generated by the ever changing demands. As a matter fact, the introduction of new technologies might also play a significant role, especially for teachers with many years of service, who may have had to experience several difficulties to adopt. Overall, this good generate among private school teacher a considerable work load, less salary and difficulties to adopt, which become more significant for the employees.

The co-worker, head, institution and family relationships have little influence on teachers' commitment to a working station. However, they have important policy implications for human resource management practitioners and administrators of schools. Conducive social environment needs to be created in the work settings to enhance commitment of employees. They also need to find solutions for various issues by organizationally supported teachers when necessary and by using management knowledge and skills. The study elicited many factors responsible for job satisfaction and for the changes in the attitude of teachers.

Management of public schools should ensure that performance evaluations are fair and unbiased. Therefore, promotions based on merits and performance evaluation will be perceived by academicians as equitable and fair, and result in a greater degree of job satisfaction and higher degree of productivity. It is in the best interests of public schools to retain and promote the best qualified employees. The study concludes that among all the categories of teachers have better job satisfactions in many aspects. Overall public school teachers are more flexible and satisfied with their working hours and working conditions as compared to private school teachers.

\section{RECOMMENDATIONS}

- The organizational support towards teachers should be enhanced both in quality and quantity.

- Special emphasis should be placed upon supportive work that helps teachers' selfdevelopment.

- Female teachers should be supported to augment their organizational commitment in the most convenient way for their needs.

- Short term courses, conference and seminar should be organized to refresh and motivate teachers in both sectors.

- Teacher's efforts should be highly appreciated by the heads of the school. 


\section{ACKNOWLEDGEMENT}

The work was made possible with the doctoral fellowship from Indian Council of Social Science Research, New Delhi.

\section{REFERENCES}

[1] Imbert Caroline (2004) Psychological Well-Being and Job Satisfaction Amongst Military Personnel on Unaccompanied Tours : The Impact of Perceived Social Support and Coping Strategies, Military Psychology, Vol. 16, no.1 :37- 51

[2] Jocelyn Sackey (2011) Social Support as Mental Health Improver forManagerial Women in the Organizational WorkEnvironment, Business Intelligence Journal- July, 2011 Vol.4 No.2:355-361

[3] JampaVenkata Rama Chandra Rao (2015) Job Satisfaction Among the Secondary School Teachers, International Journal of Academic Research, Vol.2, Issue-2(5), April-June, 2015

[4] KeowNgangT and Lye Phei See (2013) Principal Support on Teacher Collective Work in Chinese Private Secondary Schools, Procedia - Social and Behavioral Sciences 97:299 306

[5] Rajalingam (2014) Impact Of Students' Profile on Job Satisfaction of the Teachers in Tirunelveli District, International Journal of Business and Administration Research Review, Vol.1, Issue.5:109, April-June.

[6] SandeepKataria (2014) Job satisfaction among Government and Private School Teachers, Educationia Confab, Vol. 3, No. 6:6-11, June.

[7] SehreshIqbal (2015) Impact of Perceived Organizational Support on Employee Retention with Mediating Role of Psychological Empowerment, Pakistan Journal of Commerce and Social Sciences 2015, Vol. 9 (1): 18-34.

[8] RastegarKhaled(2005). Extension Role of Women in Direction of Job and Family Supports, sociological Quarterly, Iran. 6thyear, No4: 126-165. 